\title{
Efficacy and safety of a biodegradable polymer sirolimus-eluting stent in primary percutaneous coronary intervention: a randomized controlled trial
}

Qiang Li, Zichuan Tong, Lefeng Wang, Jianjun Zhang, Yonggui Ge, Hongshi Wang, Weiming Li, Li Xu, Zhuhua Ni, Xinchun Yang

Department of Cardiology, Beijing Chaoyang Hospital, Capital Medical University, Beijing, China

Submitted: 30 August 2012

Accepted: 6 November 2012

Arch Med Sci 2013; 9, 6: 1040-1048

DOI: 10.5114/aoms.2013.39793

Copyright $\odot 2013$ Termedia \& Banach

\section{Abstract}

Introduction: With long-term follow-up, whether biodegradable polymer drugeluting stents (DES) is efficient and safe in primary percutaneous coronary intervention $(\mathrm{PCl}$ ) remains a controversial issue. This study aims to assess the longterm efficacy and safety of DES in PCI for ST-segment elevation myocardial infarction (STEMI).

Material and methods: A prospective, randomized single-blind study with 3-year follow-up was performed to compare biodegradable polymer DES with durable polymer DES in 332 STEMI patients treated with primary $\mathrm{PCI}$. The primary end point was major adverse cardiac events (MACE) at 3 years after the procedure, defined as the composite of cardiac death, recurrent infarction, and target vessel revascularization. The secondary end points included in-segment late luminal loss (LLL) and binary restenosis at 9 months and cumulative stent thrombosis (ST) event rates up to 3 years.

Results: The rate of the primary end points and the secondary end points including major adverse cardiac events, in-segment late luminal loss, binary restenosis, and cumulative thrombotic event rates were comparable between biodegradable polymer DES and durable polymer DES in these 332 STEMI patients treated with primary $\mathrm{PCl}$ at 3 years.

Conclusions: Biodegradable polymer DES has similar efficacy and safety profiles at 3 years compared with durable polymer DES in STEMI patients treated with primary $\mathrm{PCl}$.

Key words: biodegradable polymer drug-eluting stents, percutaneous coronary intervention.

\section{Introduction}

Drug-eluting stents (DES) have been proven to be effective in primary percutaneous coronary intervention $(\mathrm{PCl})$ in the treatment of patients with ST-segment elevation myocardial infarction (STEMI) by several randomized trials with mid-term follow-up [1-3]. The major safety concern about DES is the infrequent but catastrophic complications such as acute thrombosis hours or days after myocardial infarction, late stent thrombosis (LST) and very late stent thrombosis (VLST) [4]. Furthermore, events of LST are more frequently reported after primary stenting than after elective stenting [5]. However, with long-term follow-up, whether DES is efficient and safe in $\mathrm{PCl}$ remains a controversial issue [6-8].

\author{
Corresponding author: \\ Dr. Xinchun Yang \\ Department of Cardiology \\ Beijing Chaoyang Hospital \\ Capital Medical University \\ No. 8 Gongtinan Road \\ Beijing 100020, China \\ Phone: 0086-(0) 10-85231937 \\ Fax: 0086-(0) 10-85231937 \\ E-mail: xinchunyang_bj@ \\ hotmail.com
}


The durable polymer surface coatings used in the first generation of DES potentially contribute to persistent inflammation and impaired endothelialization, and thereby lead to LST [9]. The new generation of DES coated with biodegradable polymer, with only a bare-metal platform remaining after drug delivery and subsequent complete polymer degradation, might theoretically help reduce the risk of LST. Efficacy of biodegradable polymer DES has been reported $[10,11]$.

This study aims to evaluate the long-term efficacy and safety of the biodegradable polymer DES (Excel, JW Medical System, Weihai, China) in primary $\mathrm{PCl}$ for treatment of STEMI patients, based on a 3-year clinical follow-up, compared with the durable polymer DES (Cypher Select, Cordis Corporation, Miami Lakes, Fla).

\section{Material and methods}

This study was approved by the Local Human Research Ethics Board in Beijing, China, and all participants gave written informed consent before being enrolled in the study.

\section{Study design}

This is a single-center, open-labeled, randomized prospective study. This study aims to evaluate the clinical and angiographic results in STEMI patients undergoing primary $\mathrm{PCl}$ with biodegradable polymer coated DES. Primary PCI was performed by 6 experienced operators during May 2007 to Dec 2008.

\section{Study population and randomization}

Consecutive patients were included if they were $>18$ years of age, had symptoms of acute $\mathrm{MI}$ for $\geq 30 \mathrm{~min}$ but $\leq 12 \mathrm{~h}$, and had the electrocardiogram showing ST-segment elevation (at least $1 \mathrm{~mm}$ in two or more standard leads or at least $2 \mathrm{~mm}$ in two or more contiguous precordial leads) or left bundle-branch block. Exclusion criteria were: 1) cardiogenic shock (systolic blood pressure $<80 \mathrm{~mm} \mathrm{Hg}$ for $>30$ min or need for intravenous pressors or intra-aortic balloon counterpulsation); 2) left main coronary artery or graft disease; 3 ) previous $\mathrm{PCl}$ or coronary artery bypass grafting of the infarct-related artery; 4) thrombolytic therapy for the index infarction; 5) target vessel reference diameter $<2.5 \mathrm{~mm}$ or $>3.5 \mathrm{~mm}$; 6) a history of bleeding diathesis, leukopenia, thrombocytopenia, or severe hepatic or renal dysfunction; 7) contraindication to the use of aspirin, clopidogrel, heparin, or tirofiban; 8) participation in another study; or 9) life expectancy $<12$ months.

Once blood flow was established (spontaneously or by balloon inflation), the operator determined whether the patient qualified for randomization.
Using the Statistics Analysis System (SAS) software, a randomization table was generated with a block randomization procedure provided by an independent statistician who was unaware of the study subjects. Each subject received a number within a concealed envelope indicating the randomization assignment. The study employed a two-group design, including a biodegradable polymer DES group and a durable polymer DES group. According to the sample size equation $n=(\sigma / \Delta)^{2} \times\left(Z_{\alpha / 2}+Z_{\beta}\right)^{2}$, $\alpha=0.05, Z_{\alpha / 2}=1.96, \beta=0.1, Z_{\beta}=1.65$, the sample size was determined considering the primary endpoint in this study. Combined with our previous drop-out rate, 338 individuals were equally assigned to the biodegradable polymer DES group and the durable polymer DES group. The statistical power level was set to 0.80 , and the statistical significance level was set at 0.05 .

\section{Device description}

The Excel stent is a sirolimus-eluting stent (SES) coated with a biodegradable polylactic acid (PLA) polymer and its feature has been described elsewhere [12]. The PLA polymer resorption is complete in the porcine model by 6 to 9 months, thus leaving only the bare-metal platform in perpetuity. Its sustained efficacy and safety have been documented [13].

\section{Catheterization and study procedure}

Before the procedure, all patients received $300 \mathrm{mg}$ of aspirin and 300 to $600 \mathrm{mg}$ of clopidogrel. Administration of both aspirin and clopidogrel was started in the same phase in all patients in the catheterization lab. The procedure was performed through the femoral or radial artery at the operator's discretion using standard techniques. Lesions were treated according to current interventional practice and stent size and length selection was based on visual estimation. If more than 1 stent was required, the same type of stent was used. Direct stenting was allowed and dilatation after stent placement was at the operator's discretion. Heparin was administered throughout the procedure in order to maintain an activated clotting time of $250 \mathrm{~s}$ or longer. Administration of platelet glycoprotein IIb/IIla-receptor inhibitors was left to the investigator's discretion.

\section{Follow-up}

Clinical follow-up was performed at 30 days, 3 months, 6 months, and then every 6 months for a total of 3 years after the procedure. Aspirin (75 to $100 \mathrm{mg} /$ day) was prescribed indefinitely and clopidogrel ( $75 \mathrm{mg} /$ day) for at least 12 months. The duration of treatment of both drugs was comparable in two study groups. Patients were treated with 
$\beta$-blocking agents, statins, and angiotensin-converting enzyme inhibitors or angiotensin II blockers according to the judgment of the patient's physician. Follow-up angiography at 9 months was recommended to all patients.

\section{Quantitative coronary angiography (QCA) analysis}

Technicians unaware of treatment assignment analyzed all angiographic images using an automated edge-detection system (CMS version 7.1, Medis Medical Imaging Systems). Late luminal loss (LLL) was calculated as the difference between the minimum luminal diameter immediately after the procedure and at 9-month angiographic follow-up. Binary restenosis was defined as $\geq 50 \%$ reduction of the initial lumen diameter in the target lesion inside or at the proximal and distal $5 \mathrm{~mm}$ of the stent at 9 months. Flow in the infarct-related vessel was graded according to the Thrombolysis in Myocardial Infarction (TIMI) trial classification.

\section{End points}

The primary end point of this study was major adverse cardiac events (MACE), defined as the composite of cardiac death, recurrent infarction, and target vessel revascularization at 3 years. The clinical events committee whose members were blinded to the assigned stent type reviewed and adjudicated all serious clinical events, including stent thrombosis. Target-vessel revascularization was defined as repeated $\mathrm{PCl}$ or bypass grafting of the target vessel, driven by anginal symptoms and/or functional ischemia with $\geq 50 \%$ stenosis of the reference luminal diameter or $\geq 70 \%$ diameter stenosis irrespective of the presence or absence of ischemic signs or symptoms. The definition of cardiac death included death from acute myocardial infarction, cardiac perforation, or pericardial tamponade; an arrhythmia or conduction abnormality; complications of the interventional procedure at baseline; stroke (including bleeding) within 30 days after the procedure or in connection with the procedure; and all deaths that could not be clearly attributed to a non-cardiac cause. Recurrent infarction was defined as the recurrence of clinical symptoms or the occurrence of electrocardiographic changes accompanied by a new elevation in levels of creatine kinase, creatine kinase MB enzyme, or both. The level of creatine kinase required for the diagnosis of reinfarction depended on the interval from the index infarction: the creatine kinase level had to be at least 1.5 times the previous value if new symptoms appeared within $48 \mathrm{~h}$ and at least 3 times the upper limit of normal if new symptoms appeared after $48 \mathrm{~h}[14,15]$.
The secondary end points included in-segment late luminal loss and binary restenosis at 9 months angiographic follow-up, and cumulative thrombotic event rates up to 3 years after the index procedure. Stent thrombosis (ST) was classified as definite, probable, or possible according to the Academic Research Consortium (ARC) definition [16], further subdivided into early ( 0 to 30 days), late ( $>30$ days to 1 year), and very late (> 1 year) stent thrombosis.

\section{Statistical analysis}

All analyses were conducted according to the intention-to-treat principle. Continuous data were expressed as mean \pm SD or as median (interquartile range); dichotomous data were presented as numbers and percentages. All continuous variables were compared with Student's $t$ test or, in the case of a non-Gaussian distribution, with a nonparametric test. Categorical variables were compared using Pearson's $\chi^{2}$ test or Fisher's exact test as appropriate. Event-free survival curves were generated by the Kaplan-Meier method, and survival between groups was compared with the log-rank test. Hazard ratios (HRs) with $95 \%$ confidence intervals $(\mathrm{Cls})$ were calculated by the Cox proportional hazards regression model. A 2-sided $p$ value $<0.05$ was considered significant for all tests. All analyses were conducted using SPSS version 16.0 (SPSS, Inc., Chicago, Illinois).

\section{Results}

\section{Patients}

A total of 338 STEMI patients were enrolled in this study. Five patients were subsequently excluded because the assigned study stent was not available and another one was excluded because of the inability to cross the lesion with an Excel stent (Figure 1). Data of 332 patients (168 assigned to the Cypher group and 164 assigned to the Excel group) were analyzed finally. The 2 groups were well matched (Table I) though a higher percentage of patients in the Excel group had hypercholesterolemia ( $46.3 \%$ vs. $32.7 \%, p=0.013)$. In addition, there were more patients with triple-vessel disease (though not significant) in the Cypher group, which might have influenced the results.

\section{Procedural results}

Procedural characteristics are summarized in Table II. The rate of procedural success according to angiographic criteria (<30\% residual stenosis, TIMI flow grade 3) was similar between the two groups: 95.1\% (Excel) and 94.0\% (Cypher) $(p=0.810)$. Total stent length and stent diameter also did not statistically differ between the two groups. 


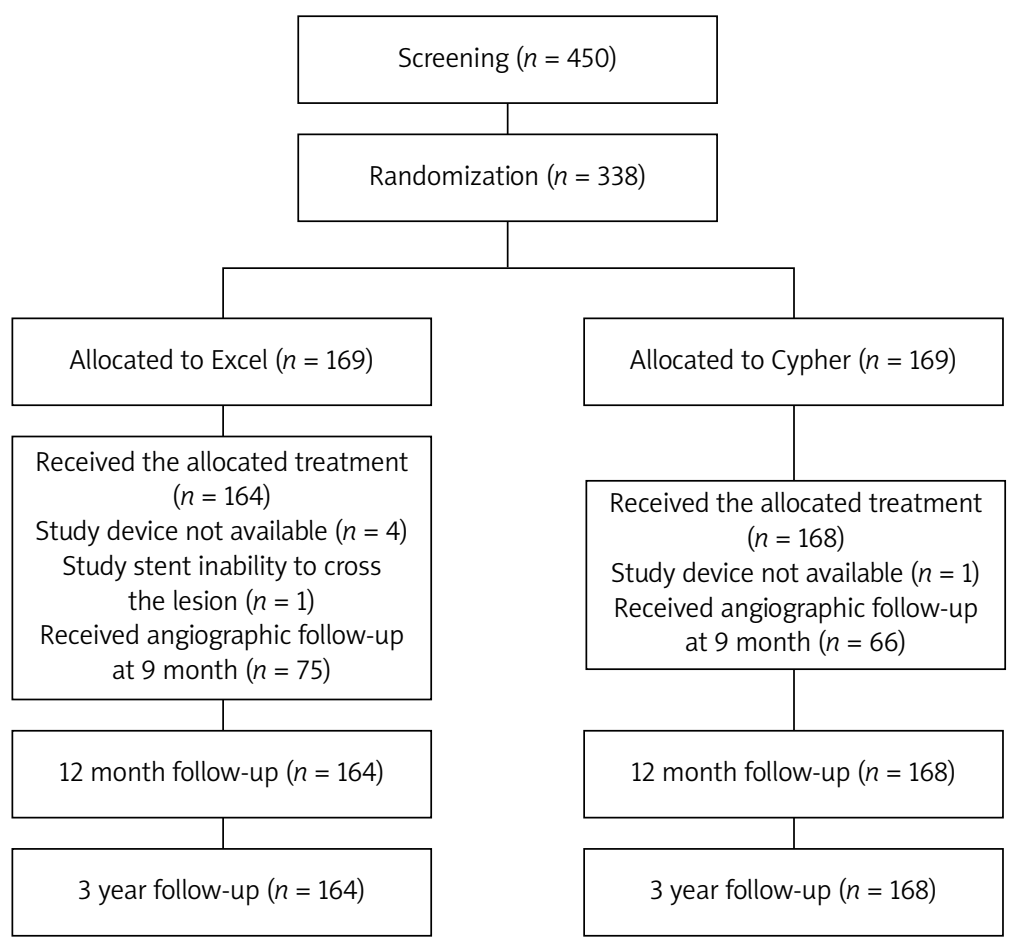

Primary exclusion ( $n=112)$

- Clinical criteria $(n=55)$

- Angiographic criteria $(n=42)$

- Refusal to participate $(n=15)$

Figure 1. Flow of participants through the trial

Table I. Clinical characteristic of patients

\begin{tabular}{|c|c|c|c|}
\hline Parameter & Excel $(n=164)$ & Cypher $(n=168)$ & Value of $p$ \\
\hline Age [years] & $59.95 \pm 11.19$ & $59.77 \pm 11.79$ & 0.892 \\
\hline Male gender & $122(74.4)$ & $130(77.4)$ & 0.608 \\
\hline Hypertension & $95(57.9)$ & $87(51.8)$ & 0.272 \\
\hline Hypercholesterolemia & $76(46.3)$ & $55(32.7)$ & 0.013 \\
\hline Diabetes mellitus & $43(26.2)$ & $55(32.7)$ & 0.229 \\
\hline Current smoker & $108(65.9)$ & $102(60.7)$ & 0.363 \\
\hline Family history of CAD & $22(13.4)$ & $26(15.5)$ & 0.641 \\
\hline Prior myocardial infarction & $9(5.5)$ & $7(4.2)$ & 0.617 \\
\hline Prior CABG & $2(1.2)$ & 0 & 0.243 \\
\hline Prior $\mathrm{PCl}$ & $5(3.0)$ & $4(2.4)$ & 0.748 \\
\hline Time from symptom onset to balloon & $6.5 \pm 6.4$ & $6.7 \pm 6.3$ & 0.425 \\
\hline \multicolumn{4}{|l|}{ Killip class } \\
\hline 1 & $110(67.1)$ & $122(72.6)$ & 0.284 \\
\hline II & $42(25.6)$ & $36(21.4)$ & 0.437 \\
\hline III & $12(7.3)$ & $10(6.0)$ & 0.664 \\
\hline Extent of coronary disease & & & 0.247 \\
\hline Single-vessel disease & $41(25.0)$ & $33(19.6)$ & 0.291 \\
\hline Double-vessel disease & $53(32.3)$ & $46(27.4)$ & 0.339 \\
\hline Triple-vessel disease & $70(42.7)$ & $89(53.0)$ & 0.063 \\
\hline \multicolumn{4}{|l|}{ Infarct-related vessel } \\
\hline Left anterior descending artery & $79(48.2)$ & $72(42.9)$ & 0.378 \\
\hline Left circumflex artery & $27(16.5)$ & $25(14.9)$ & 0.763 \\
\hline Right coronary artery & $58(35.3)$ & $71(42.2)$ & 0.216 \\
\hline LVEF(\%) & $46.9 \pm 7.2$ & $45.5 \pm 6.9$ & 0.651 \\
\hline
\end{tabular}


Table II. Procedural characteristics

\begin{tabular}{|lccc|}
\hline Variable & Excel $(n=164)$ & Cypher $(n=168)$ & Value of $p$ \\
\hline Procedural success per patient & $95.1 \%$ & $94.0 \%$ & 0.810 \\
\hline No. of lesions treated & 167 & 172 & 0.571 \\
\hline No. of stents implanted & $1.30 \pm 0.53$ & $1.34 \pm 0.56$ & 0.383 \\
\hline Stent length [mm] & $22.97 \pm 11.85$ & $24.25 \pm 10.21$ & 0.456 \\
\hline Stent diameter [mm] & $2.94 \pm 0.35$ & $3.01 \pm 0.37$ & \\
\hline Quantitative coronary analysis & & & 0.758 \\
\hline Before procedure & & & \\
\hline TIMl flow & & $120(71.4)$ & \\
\hline Grade 0 or 1 & $117(71.3)$ & $26(15.0)$ & 0.325 \\
\hline Grade 2 & $29(17.7)$ & $22(13.4)$ & 0.614 \\
\hline Grade 3 & $18(11.0)$ & $2.93 \pm 0.54$ & 0.702 \\
\hline Diameter of reference vessel & $2.84 \pm 0.56$ & $0.27 \pm 0.35$ & 0.272 \\
\hline Minimal luminal diameter & $0.24 \pm 0.39$ & $91.0 \pm 12.3$ & 0.194 \\
\hline Stenosis, \% of luminal diameter & $92.2 \pm 12.6$ & & 0.648 \\
\hline Immediately after procedure & & $2.75 \pm 0.40$ & 0.638 \\
\hline TIMl flow & $2.68 \pm 0.38$ & $158(94.0)$ & \\
\hline Grade 0 or 1 & $10.2 \pm 0.67$ & $3.04 \pm 0.49$ & \\
\hline Grade 2 & $2.45 \pm 0.51$ & & \\
\hline Grade 3 & $156(95.1)$ & & \\
\hline Diameter of reference vessel & $2.98 \pm 0.52$ & & \\
\hline Minimal luminal diameter & & & \\
\hline Stenosis, \% of luminal diameter & & & \\
\hline Acute gain & & & \\
\hline
\end{tabular}

\section{Angiographic results}

At 9 months after the procedure, 75 (45.7\%) patients in the Excel group and 69 (41.1\%) patients in the Cypher group received follow-up angiography. The median time to angiographic follow-up was 265 days (248 to 292 days) in the Excel group and 274 days (261 to 288 days) in the Cypher group ( $p=$ $0.562)$. The rates of restenosis in in-stent (4.0\% vs. $2.9 \%$, respectively; $p=0.671$ ) and in in-segment (6.7\% vs. $5.8 \%$, respectively; $p=0.738)$ were comparable between the Excel group and Cypher group. There were no significant differences in LLL both in in-stent $(0.16 \pm 0.40 \mathrm{~mm}$ vs. $0.14 \pm 0.37 \mathrm{~mm}$, respectively; $p=0.483)$ and in in-segment $(0.19 \pm 0.44 \mathrm{~mm}$ vs. $0.18 \pm 0.39 \mathrm{~mm}$, respectively; $p=0.519$ ) between the two groups (Table III).

\section{Clinical events}

In-hospital adverse events were infrequent, with no significant difference between groups (Table IV). In-hospital death occurred in 1 Excel patient and 3 Cypher patients $(0.6 \%$ vs. $1.8 \%$, respectively; $p=$ $0.623)$. One patient $(0.6 \%)$ in the Cypher group had a reinfarction due to angiographically documented

Table III. Angiographic results at 9-month follow-up

\begin{tabular}{|lccc|}
\hline Variable & Excel $(n=75)$ & Cypher $(n=69)$ & Value of $p$ \\
\hline \begin{tabular}{l} 
Late luminal loss, mean \pm SD $[\mathrm{mm}]$ \\
\hline In stent
\end{tabular} & $0.16 \pm 0.40$ & $0.14 \pm 0.37$ & 0.483 \\
\hline In segment & $0.19 \pm 0.44$ & $0.18 \pm 0.39$ & 0.519 \\
\hline $\begin{array}{l}\text { Angiographic restenosis, } n(\%) \\
\text { In stent }\end{array}$ & $3(4.0)$ & $2(2.9)$ & 0.671 \\
\hline In segment & $5(6.7)$ & $4(5.8)$ & 0.738 \\
\hline
\end{tabular}


Table IV. Clinical outcomes at 1-year and 3-year follow-up

\begin{tabular}{|c|c|c|c|}
\hline Outcomes & Excel $(n=164)$ & Cypher $(n=168)$ & Value of $p$ \\
\hline \multicolumn{4}{|c|}{ At hospital discharge } \\
\hline Death & $1(0.6)$ & $3(1.8)$ & 0.623 \\
\hline Cardiac & $1(0.6)$ & $2(1.2)$ & 1.000 \\
\hline Noncardiac & 0 & $1(0.6)$ & 1.000 \\
\hline Reinfarction & $1(0.6)$ & $1(0.6)$ & 1.000 \\
\hline TLR & $1(0.6)$ & $1(0.6)$ & 1.000 \\
\hline TVR & $1(0.6)$ & $1(0.6)$ & 1.000 \\
\hline MACES & $2(1.2)$ & $3(2.4)$ & 1.000 \\
\hline \multicolumn{4}{|l|}{ At 1 year } \\
\hline Death & $3(1.8)$ & $5(3.0)$ & 0.723 \\
\hline Cardiac & $3(1.8)$ & $4(2.4)$ & 1.000 \\
\hline Noncardiac & 0 & $1(0.6)$ & 1.000 \\
\hline Reinfarction & $3(1.8)$ & $4(2.4)$ & 1.000 \\
\hline TLR & $4(2.4)$ & $6(3.6)$ & 0.750 \\
\hline TVR & $6(3.7)$ & $7(4.2)$ & 1.000 \\
\hline MACES & $10(6.1)$ & $12(7.1)$ & 0.826 \\
\hline \multicolumn{4}{|l|}{ At 3 year } \\
\hline Death & $6(3.7)$ & $8(4.8)$ & 0.786 \\
\hline Cardiac & $4(2.4)$ & $6(3.6)$ & 0.750 \\
\hline Noncardiac & $2(1.2)$ & $2(1.2)$ & 1.000 \\
\hline Reinfarction & $6(3.7)$ & $9(5.4)$ & 0.599 \\
\hline TLR & $8(4.9)$ & $10(0.6)$ & 0.810 \\
\hline TVR & $10(6.1)$ & $11(6.5)$ & 1.000 \\
\hline MACES & $17(10.4)$ & $20(11.9)$ & 0.728 \\
\hline Stent thrombosis & $5(3.0)$ & $8(4.8)$ & 0.574 \\
\hline Definite & $2(1.2)$ & $4(1.8)$ & 0.685 \\
\hline Probable & $2(1.2)$ & $2(1.8)$ & 1.000 \\
\hline Possible & $1(0.6)$ & $2(1.2)$ & 1.000 \\
\hline Early & $2(1.2)$ & $3(1.8)$ & 1.000 \\
\hline Late & $2(1.2)$ & $1(0.6)$ & 0.619 \\
\hline Very Late & $1(0.6)$ & $4(2.4)$ & 0.371 \\
\hline
\end{tabular}

stent thrombosis. Clinical follow-up was complete for all patients over 3-year duration. There was no significant difference between the Excel group and the Cypher group in the rate of death, recurrent myocardial infarction, target vessel revascularization (TVR), MACE and ST (6.1\% vs. $6.5 \%$, respectively; $p=1.000)$ at 3-year follow-up (Table IV, Figure 2). The survival rate free from MACE was $89.6 \%$ and $88.1 \%$ in Excel and Cypher groups at 3 years ( $p=0.728, \mathrm{HR} 0.772$, 95\% Cl: 0.458-1.337). The 3-year cumulative incidence of ST was $3.0 \%$ and $4.8 \%$ in Excel and Cypher groups ( $p=0.574, \mathrm{HR} 0.485,95 \% \mathrm{Cl}: 0.374-0.962)$ and was also similar at different time intervals (early, late, and very late) between 2 groups (Table IV).

\section{Discussion}

The catastrophic event of LST occurs steadily at an annual rate of $0.4 \%$ to $0.6 \%$ for at least up to 4 years after DES implantation [4]. Although the mechanisms of LST are multifactorial and have not yet been clarified, the durable polymers used in first-generation DES, associated with persistent localized vascular inflammation, delayed endothelialization, and thrombogenic reactions, seem to play an important role. Therefore, there is growing interest in developing new generation DES with biodegradable polymers, which may overcome this potential shortcoming of durable polymer DES. 

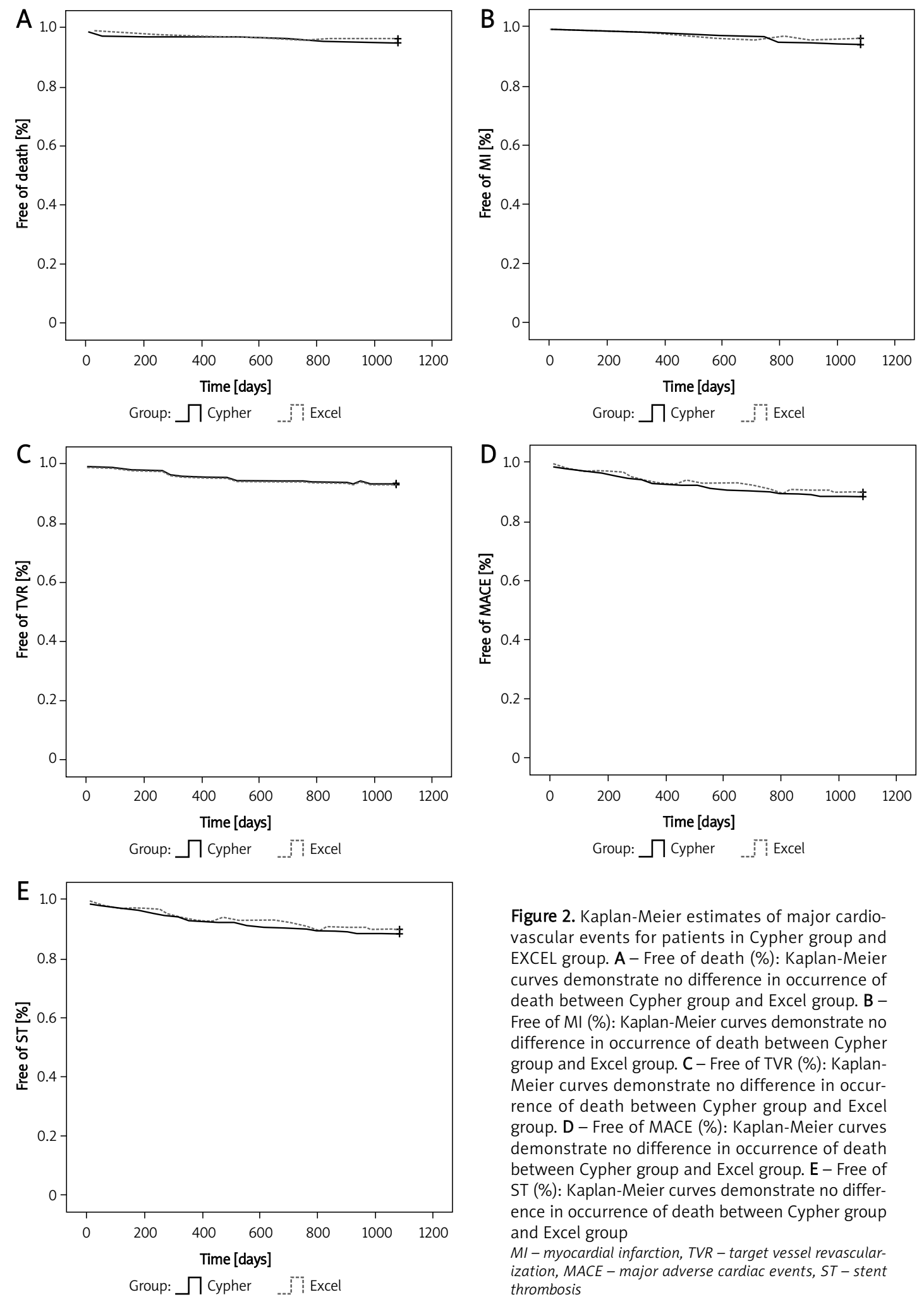

To the best of our knowledge, this is the first randomized prospective study evaluating the efficacy and safety of the biodegradable polymer SES in STEMI patients undergoing primary angioplasty with a long-term follow-up (3 years). The Excel stent in the study is a new generation SES coated with

Figure 2. Kaplan-Meier estimates of major cardiovascular events for patients in Cypher group and EXCEL group. A - Free of death (\%): Kaplan-Meier curves demonstrate no difference in occurrence of death between Cypher group and Excel group. B Free of MI (\%): Kaplan-Meier curves demonstrate no difference in occurrence of death between Cypher group and Excel group. C - Free of TVR (\%): KaplanMeier curves demonstrate no difference in occurrence of death between Cypher group and Excel group. D - Free of MACE (\%): Kaplan-Meier curves demonstrate no difference in occurrence of death between Cypher group and Excel group. E - Free of ST (\%): Kaplan-Meier curves demonstrate no difference in occurrence of death between Cypher group and Excel group

MI - myocardial infarction, TVR - target vessel revascularization, MACE - major adverse cardiac events, ST - stent thrombosis

a biodegradable polymer (PLA). In this single-center study for STEMI patients treated with primary $\mathrm{PCl}$, Excel showed competitive effectiveness in clinical events in 3 years and showed similar angiographic LLL and restenosis rate at 9 months compared with Cypher Select. 
A bioabsorbable polymer paclitaxel-eluting stent (PES) was demonstrated to have promising clinical efficacy and safety at 6 months in the STELLIUM I study [17], while in the COSTAR II study, another absorbable polymer PES showed higher risk of binary stenosis and TVR [18]. Long-term follow-up of ISAR-TEST-3 and ISAR-TEST-4 trials showed noninferiority of biodegradable polymer SES in efficacy compared with durable polymer SES [10, 11]. Angiographic outcomes of the ISAR-TEST-4 trial at 68 months showed similar LLL and restenosis between the two types [11]. In a multicentre study, Biolimuseluting stent (BES) with biodegradable polymer displayed non-inferiority in overall cardiac event rates compared with durable polymer SES [19]. To date, most studies have shown that biodegradable polymer DES were non-inferior to permanent polymer DES in efficacy $[10,11,18,19]$.

Although biodegradable polymer DES might theoretically act as a bare metal stent (BMS) after drug delivery and polymer degradation and potentially decrease the occurrence of LST, current studies have not yet confirmed the superiority of biodegradable polymer over durable polymer DES in ST events, even with long-term follow-up. Biodegradable polymer and permanent polymer SES were associated with similar rates of ST at 2 years in the ISAR-TEST 3 trial and at 3 years in the ISAR-TEST 4 trial $[10,11]$. During 4-year follow-up of the LEADERS trial [20], biodegradable polymer BES showed a comparable overall ST rate to durable polymer SES. However, in the LEADERS trial during 1-4 years after stent implantation, biodegradable polymer BES showed a significantly lower risk of very late definite and very late definite/probable ST compared with durable polymer SES, with the rate of very late definite ST as $0.12 \%$ per year vs. $0.6 \%$ per year respectively [21]. A recent pooled analysis of the ISAR-TEST 3, ISAR-TEST 4 and LEADERS trials demonstrated that biodegradable polymer DES reduced the risk of ST at 4 years, driven by lower risk of VLST [22]. A systematic review and meta-analysis of 13 randomized trials with 7,352 patients and 18 registry studies with 26,521 patients has demonstrated that the use of first generation DES in STEMI patients appears safe and efficacious, without an increase in ST within 2 years compared to BMS [23]. In the present study, the Excel group displayed a similar rate of ST compared to Cypher. This might be due to the low rate of ST and the small sample size of the present study.

Another appealing advantage of biodegradable polymer DES is the potential for shortening dual antiplatelet therapy (DAPT) duration. Current guidelines recommend that DAPT should be given for at least 12 months following DES placement unless patients are at high risk for bleeding. Focusing on the DAPT regime after new generation DES place- ment, some studies have shown that 6-month DAPT would be safe in patients treated with zotarolimuseluting or everolimus-eluting stents [24, 25]. The CREAT registry reported that with 6 months (mean duration $199.8 \pm 52.7$ days) of DAPT, Excel had sustained clinical safety to 3 years. But considering the lifethreatening complication of LST, one must cautiously shorten the DAPT period after implantation of DES. According to the recommendation of current guidelines, we advocated 12-month DAPT in this study after STEMI in patients receiving either biodegradable polymer DES or permanent polymer DES, with mean duration of DAPT as $389.6 \pm 67.9$ days in Excel patients and $394.8 \pm 71.4$ days in Cypher patients. At 12 months, $83.2 \%$ (134/161) of Excel patients and $80.4 \%(131 / 163)$ of Cypher patients discontinued clopidogrel. It will be promising if a biodegradable polymer DES can act safely enough with less dependency on DAPT. As it may be device-specific, optimal duration of DAPT after biodegradable polymer DES placement remains to be further clarified.

Several potential limitations of this study should be highlighted. First, this is a relatively small sample in a single-center study. As the occurrence rate of late and very late in-stent thrombosis is low, the study is largely underpowered to analyze these types of very rare events. A larger, multicenter study is highly needed to clarify this point. Second, an angiographic primary end-point would be better for this number of patients with for example OCT control of endothelialization. However, the angiography rate during the follow-up stage is low. For example, follow-up angiography at 9 months was recommended to all patients. However, less than $50 \%$ of patients underwent angiography. Nevertheless, considering the results from this study and also the most recent study, the COMFORTABLE AMI randomized trial, which showed that the use of Biolimus-eluting stents with a biodegradable polymer could result in a lower rate of the composite of major adverse cardiac events at 1 year among patients with STEMI undergoing primary $\mathrm{PCI}$ [26], biodegradable polymer DES is recommended for STEMI patients undergoing primary $\mathrm{PCl}$.

In conclusion, biodegradable polymer DES has similar efficacy and safety profiles at 3 years compared with durable polymer DES in STEMI patients treated with primary $\mathrm{PCl}$.

\section{Acknowledgments}

Qiang Li and Zichuan Tong contributed equally to this work.

\section{References}

1. Spaulding C, Henry P, Teiger E, et al. Sirolimus-eluting versus uncoated stents in acute myocardial infarction. N Engl J Med 2006; 355: 1093-104. 
2. van der Hoeven BL, Liem SS, Jukema JW, et al. Sirolimuseluting stents versus bare-metal stents in patients with ST-segment elevation myocardial infarction: 9-month angiographic and intravascular ultrasound results and 12-month clinical outcome results from the MISSION, Intervention Study. J Am Coll Cardiol 2008; 51: 618-26.

3. Stone GW, Lansky AJ, Pocock SJ, et al. Paclitaxel-eluting stents versus bare-metal stents in acute myocardial infarction. N Engl J Med 2009; 360: 1946-59.

4. Wenaweser P, Daemen J, Zwahlen $M$, et al. Incidence and correlates of drug-eluting stent thrombosis in routine clinical practice 4-year results from a large 2-institutional cohort study. J Am Coll Cardiol 2008; 52: 1134-40

5. Park DW, Park SW, Park KH, et al. Frequency of and risk factors for stent thrombosis after drug-eluting stent implantation during long-term follow-up. Am J Cardiol 2006; 98: 352-6.

6. Spaulding C, Teiger E, Commeau P, et al. Four-year followup of TYPHOON (trial to assess the use of the CYPHer sirolimus-eluting coronary stent in acute myocardial infarction treated with BallOON angioplasty). JACC Cardiovasc Interv 2011; 4: 14-23.

7. Atary JZ, van der Hoeven BL, Liem SS, et al. Three-year outcome of sirolimus-eluting versus bare-metal stents for the treatment of ST-segment elevation myocardial infarction (from the MISSION! Intervention Study). Am J Cardiol 2010; 106: 4-12.

8. Brodie B, Pokharel Y, Fleishman N, et al. Very late stent thrombosis after primary percutaneous coronary intervention with bare-metal and drug-eluting stents for ST-segment elevation myocardial infarction: a 15-year single-center experience. JACC Cardiovasc Interv 2011; 4: 30-8.

9. Virmani R, Guagliumi G, Farb A, et al. Localized hypersensitivity and late coronary thrombosis secondary to a sirolimus-eluting stent: should we be cautious? Circulation 2004; 109: 701-5.

10. Byrne RA, Kufner S, Tiroch K, et al. Randomised trial of three rapamycin-eluting stents with different coating strategies for the reduction of coronary restenosis: 2-year follow-up results. Heart 2009; 95: 1489-94.

11. Byrne RA, Kastrati A, Massberg S, et al. Biodegradable polymer versus permanent polymer drug-eluting stents and everolimus-versus sirolimus-eluting stents in patients with coronary artery disease: 3-year outcomes from a randomized clinical trial. J Am Coll Cardiol 2011; 58: 1325-31.

12. Han $Y$, Jing $Q, X u B$, et al. Safety and efficacy of biodegradable polymer-coated sirolimus-eluting stents in "real-world" practice: 18-month clinical and 9-month angiographic outcomes. JACC Cardiovasc Interv 2009; 2: 303-9.

13. Han Y, Jing Q, Li Y, et al. Sustained clinical safety and efficacy of a biodegradable-polymer coated sirolimus-eluting stent in real-world practice: Three-Year Outcomes of the CREATE (multi-Center Registry of EXCEL Biodegradable Polymer Drug Eluting Stents) Study. Catheter Cardiovasc Interv 2012; 79: 211-6.

14. Veselka J, Hájek P, Malý M, et al. Predictors of coronary intervention-related myocardial infarction in stable angina patients pre-treated with statins. Arch Med Sci 2011; 7 : 67-72.

15. Hájek P, Macek M Sr, Lashkevich A, et al. Influence of concomitant heparin administration on pregnancyassociated plasma protein-A levels in acute coronary syndrome with ST segment elevation. Arch Med Sci 2011; 7: 977-83.
16. Cutlip DE, Windecker S, Mehran R, et al. Clinical end points in coronary stent trials: a case for standardized definitions. Circulation 2007; 115: 2344-51.

17. Kozuki A, Shite J, Shinke T, et al. STELLIUM 1: first-in-man follow-up evaluation of bioabsorbable polymer-coated paclitaxel-eluting stent. Circ J 2010; 74: 2089-96.

18. Krucoff MW, Kereiakes DJ, Petersen JL, et al. A novel bioresorbable polymer paclitaxel-eluting stent for the treatment of single and multivessel coronary disease: primary results of the COSTAR (Cobalt Chromium Stent With Antiproliferative for Restenosis) II study. J Am Coll Cardiol 2008; 51: 1543-52.

19. Kufner S, Massberg S, Dommasch M, et al. Angiographic outcomes with biodegradable polymer and permanent polymer drug-eluting stents. Catheter Cardiovasc Interv 2011; 78: 161-6.

20. Windecker S, Serruys PW, Wandel S, et al. Biolimus-eluting stent with biodegradable polymer versus sirolimus-eluting stent with durable polymer for coronary revascularisation (LEADERS): a randomised non-inferiority trial. Lancet 2008; 372: 1163-73.

21. Stefanini GG, Kalesan B, Serruys PW, et al. Long-term clinical outcomes of biodegradable polymer biolimuseluting stents versus durable polymer sirolimus-eluting stents in patients with coronary artery disease (LEADERS): 4 year follow-up of a randomised non-inferiority trial. Lancet 2011; 378: 1940-8.

22. Stefanini GG, Byrne RA, Serruys PW, et al. Biodegradable polymer drug-eluting stents reduce the risk of stent thrombosis at 4 years in patients undergoing percutaneous coronary intervention: a pooled analysis of individual patient data from the ISAR-TEST 3, ISAR-TEST 4, and LEADERS randomized trials. Eur Heart J 2012; 33: 1214-22.

23. Brar SS, Leon MB, Stone GW, et al. Use of drug-eluting stents in acute myocardial infarction: a systematic review and meta-analysis. J Am Coll Cardiol 2009; 53: 1677-89.

24. Kandzari DE, Barker CS, Leon MB, et al. Dual antiplatelet therapy duration and clinical outcomes following treatment with zotarolimus-eluting stents. JACC Cardiovasc Interv 2011; 4: 1119-28.

25. Gwon HC, Hahn JY, Park KW, et al. Six-month versus 12month dual antiplatelet therapy after implantation of drug-eluting stents: the Efficacy of Xience/Promus Versus Cypher to Reduce Late Loss After Stenting (EXCELLENT) randomized, multicenter study. Circulation 2012; 125: 505-13.

26. Räber L, Kelbæk H, Ostojic M, et al. Effect of biolimuseluting stents with biodegradable polymer vs. bare-metal stents on cardiovascular events among patients with acute myocardial infarction: the COMFORTABLE AMI randomized trial. JAMA 2012; 308: 777-87. 